\title{
Effectiveness of health care package on risk factors and prevention of neonatal hypothermia in low birth weight babies in terms of knowledge and practice of postnatal mothers in a selected hospital of Nepal.
}

\author{
Ms. Shobha Sapkota ${ }^{1}$, Dr. (Mrs.) Molly Babu ${ }^{2}$, Dr. (Mrs.) Harinderjeet Goyal ${ }^{3}$ \\ ${ }^{1}$ M.sc Nursing Student, Rajkumari Amrit Kaur College Of Nursing, New Delhi India \\ ${ }^{2}$ H.O.D, Obstetrical nursing, Rajkumari Amrit Kaur College Of Nursing, New Delhi India \\ ${ }^{3}$ H.O.D, Medical Surgical nursing, Rajkumari Amrit Kaur College Of Nursing, New Delhi India
}

\begin{abstract}
A study was conducted to develop and evaluate the effectiveness of health care package on risk factors and prevention of neonatal hypothermia in low birth weight babies in terms of knowledge and practice of postnatal mothers in a selected hospital of Nepal. Research approach adopted for the study was evaluative research with pre-test and post-test control group design. The sample comprised of 60 postnatal mothers of $L B W$ babies, 30 each in experimental and control group who were selected by purposive sampling technique followed by random assignment.

Knowledge and practice of postnatal mothers were assessed before and after administration of health care package. A significant gain in post-test knowledge scores was found in experimental group as compared to control group ( $t=10.47)$. A significant improvement in practice was found in experimental group as compared to control group ( $t=14.57)$. This shows that the health care package on risk factors and prevention of neonatal hypothermia in $L B W$ babies was effective in enhancing knowledge and practice of postnatal mothers of $L B W$ babies.
\end{abstract}

Keywords: Health care package, Hypothermia, Knowledge, Low birth weight baby, Practice.

\section{Introduction}

The basic need of an infant includes love, touch, warmth, safety and security. We can say that out of all these needs warmth secures the life of an infant baby and becomes vital. The first few days of life are crucial in building the foundations of good health of a baby. At the time of delivery, when a child comes out of the sterile and warm environment of mother's uterus, his/her need of warm remains the same in the outside world. During this time, certain specific biological, psychological and physical need must be met to ensure e healthy development of the child into a future adult. Newborn period is from birth to first 28 days. It is crucial period for the survival of the baby. A timely care to be provided to that newborn, if certain things are not done in time, it will not affect the survival of that baby, but it may carry some bad effects throughout his/her life.

Thermoregulation is the ability to balance between heat production and heat loss in order to maintain body temperature within certain normal range. This ability is very limited in the newborn. Thermoregulation in the low birth weight and preterm are in disturbed due to lack of brown fat and highest heat loss than the heat production.

\section{Objectives}

The objectives of the study were

1. Evaluate the knowledge of postnatal mothers regarding risk factors and prevention of neonatal hypothermia in low birth weight babies before and after administration of health care package.

2. Evaluate the practice among postnatal mothers regarding prevention of neonatal hypothermia in low birth weight babies before and after administration of health care package.

3. Determine relationship between knowledge and practice among postnatal mothers regarding risk factors and prevention of neonatal hypothermia after administration of health care package.

\section{Conceptual Framework}

The conceptual frame work adopted for the study was based on the Orem's Self-Care Theory (1989).

\section{Review Of Literature}

Watkinson, M.(2006) ${ }^{[1]}$ The study showed that the body temperature of preterm babies can drop precipitously after delivery, and this hypothermia is associated with an increase in mortality and morbidity. 
Reports of hypothermia in babies of all birth weights, on admission to neonatal units, have come from all over the world; most also report increased mortality in association with hypothermia. Recent reports that showed that hypothermia on admission to neonatal units is an independent risk factor for mortality in preterm babies have refocused attention on the need for meticulous thermal care immediately after birth and during resuscitation.

Bhandari, U.M. et al. (2010) ${ }^{[2]}$ study was conducted to evaluate the effectiveness of PTP on prevention of hypothermia in newborn among mothers. The study revealed that knowledge scores of mothers revealed that $2(6.66 \%)$ had good knowledge, 17(56.66\%) had average knowledge and 11(36.66\%) had poor knowledge. The findings of the study concluded that the existing knowledge of the mothers towards the prevention of neonatal hypothermia is inadequate.

Shrestha, D. et al. (2008) ${ }^{[3]}$ A study conducted in rural Nepal on 5411 married women aged 15-19 years who had given birth to a live baby. $4893(90 \%)$ women gave birth at home. Attendance at delivery by skilled government health workers was low $(334,6 \%)$, as was attendance by traditional birth attendants $(267$, $5 \%)$. Only $461(8 \%)$ women had used a clean home delivery kit, and about half of attendants had washed their hands. Only $3482(64 \%)$ newborn infants had been wrapped within half an hour of birth, and $4992(92 \%)$ had been bathed within the first hour. 99\% (5362) of babies were breast fed, 91\% (4939) within six hours of birth. Thus, we can clearly say that the knowledge and practice of newborn care is inadequate.

Padiyath, M.A. (2010) ${ }^{[4]}$ study was designed to assess the knowledge and attitude of neonatal care practices among postnatal mothers in a tertiary care hospital. This descriptive study was carried out in the Neonatal Division, Department of Pediatrics of a tertiary care hospital in South India during April - July 2009. The data was collected from 100 postnatal mothers by trained interviewers using a structured Performa. The Knowledge of mothers was inadequate in areas of umbilical cord care $(35 \%)$, thermal care $(76 \%)$ and vaccine preventable diseases. $19 \%$ of them still practice oil instillation into nostrils of newborn and $61 \%$ of them administer gripe water to their babies. This study indicates that awareness and attitude of postnatal mothers towards neonatal care has lots of lacunae especially in those who belong to the lower socioeconomic status.

Tamakad, S.B. (2013) ${ }^{[5]}$ The study revealed that there was increase in all the areas of the knowledge after administration of PTP. The mean post-test knowledge score (36.6) was higher than the mean pre-test knowledge score (17.9). Thus it was inferred that PTP was the best teaching strategy as it enhance the knowledge of mothers regarding prevention of neonatal hypothermia.

\section{Research Design}

\section{Methodology}

True experimental research design was selected consisting of Pre-test Post- test control group.

\section{Setting}

The research setting selected for the study was AMDA-Siddhartha Children and Women Hospital, Nepal.

\section{Population}

The population comprised of postnatal mothers whose babies were low birth weight and admitted in a selected hospital of Nepal.

\section{Sample Size}

A total number of 60 postnatal mothers (30 in experimental \& 30 in control group) were selected.

\section{Sampling Technique}

Simple random sampling was used for selecting the subjects.

\section{Description of the Tool:}

Part I: Structured Interview Schedule for demographic data.

Part-II: Structured knowledge interview schedule to assess knowledge of postnatal mothers regarding risk factors and prevention of neonatal hypothermia.

Part-III: Structured observation checklist to assess the practice of postnatal mothers regarding prevention of neonatal hypothermia..

\section{Data Collection}

Study was conducted from $15^{\text {th }}$ December 2013 to $8^{\text {th }}$ January 2014 at a selected hospital in Nepal (AMDA-Nepal Siddhartha Children and Women hospital) after getting formal permission. The sample included 60 postnatal mothers of low birth weight baby, 30 each in experimental group and control group who were available during the period of data collection and were selected by purposive sampling technique followed by random assignment. 
Effectiveness of health care package on risk factors and prevention of neonatal hypothermia in ....

\section{Findings of the Study}

Table 1: Mean, Mean Difference, Standard Deviation Difference ( $\left.\mathrm{SD}_{\mathrm{D}}\right)$, Standard Error Mean Difference $\left(\mathrm{SE}_{\mathrm{MD}}\right.$ ) and ' $\mathrm{t}$ ' Value of Pre-test and Post-test Knowledge Score of Experimental Group N=30

\begin{tabular}{|c|c|c|c|c|c|}
\hline \multirow{2}{*}{$\begin{array}{l}\text { Experimental } \\
\text { Group }\end{array}$} & \multicolumn{5}{|c|}{ Knowledge Scores } \\
\hline & Mean & Mean D & $\mathbf{S D}_{\mathbf{D}}$ & $\mathbf{S E}_{\mathrm{MD}}$ & 't' value \\
\hline Pre test & 11.43 & 12.3 & 1.06 & .7822 & $18.85^{*}$ \\
\hline Post test & 23.73 & & & & \\
\hline
\end{tabular}

df $(29)=2.04$ significant at 0.05 level

* Significant at 0.05 level

The data presented in Table 1 shows that mean post-test knowledge score (23.73) of experimental group of postnatal mothers of LBW babies was higher than their mean pre-test knowledge scores (11.43). The obtained mean difference (12.3), between the post-test and pre-test knowledge scores of experimental group was found to be statistically significant as evident from the ' $t$ ' value 18.85 for $\mathrm{df}$ (29) at 0.05 level. Therefore, the obtained mean difference was true difference and not by chance.

Table 2: Mean, Mean Difference, Standard Deviation, Standard Error of Difference and ' $t$ ' Value of Pre Test Knowledge Scores of Experimental and Control Group. $\mathbf{N}=\mathbf{6 0}$

\begin{tabular}{|c|c|c|c|c|c|}
\hline \multirow[t]{2}{*}{ Groups } & \multicolumn{5}{|c|}{ Pre-test Knowledge Scores } \\
\hline & Mean & Mean D & Standard Deviation (SD) & $\mathrm{SE}_{\mathrm{MD}}$ & 't' value \\
\hline Experimental Group $(n=30)$ & 11.43 & \multirow[t]{2}{*}{0.6} & \multirow[t]{2}{*}{3.95} & \multirow[t]{2}{*}{1.25} & \multirow[t]{2}{*}{$0.478^{\mathrm{NS}}$} \\
\hline Control Group $(n=30)$ & 12.03 & & & & \\
\hline
\end{tabular}

The data presented in the Table 2 shows that the mean pre-test knowledge score of (11.43) of postnatal mothers of LBW babies of experimental group was higher than mean pre-test knowledge scores of postnatal mothers of control group (12.03). The obtained mean difference (0.6) between the pre-test knowledge scores of experimental and control group is found to be statistically insignificant as evident from ' $\mathrm{t}$ ' value 0.478 for $\mathrm{df}$ (58) at 0.05 level of significance.

Table 3: Mean, Mean Difference, Standard Deviation, Standard Error Mean Difference (SE $\mathrm{MD}_{\text {) }}$ and ' $\mathrm{t}$ ' Value of Post-test Knowledge Scores Between Experimental and Control Group. N=60

\begin{tabular}{|c|c|c|c|c|c|}
\hline \multirow[t]{2}{*}{ Group } & \multicolumn{5}{|c|}{ Post- test Knowledge Score } \\
\hline & Mean & Mean D & SD & $\mathbf{S E}_{\mathrm{MD}}$ & 't' value \\
\hline Experimental group $(n=30)$ & 23.73 & & & & \\
\hline Control Group $(\mathbf{n}=30)$ & 13.26 & 10.47 & 4.2 & 1.33 & 8.671* \\
\hline
\end{tabular}

$\operatorname{df}(58)=2.00, *$ Significant at 0.05 level of significance

The data presented in the Table 3 shows that the mean post-test knowledge scores (23.73) of postnatal mothers of experimental group was higher than the mean post-test knowledge score of control group (13.26). The obtained mean difference (10.47) between the post-test knowledge scores of experimental and control group was found to be statistically significant as evident from ' $t$ ' value of 8.671 for $\mathrm{df}(58)$ at 0.05 level of significance.

Table 4: Mean Difference, Standard Deviation (SD), Standard Error Difference (SE ${ }_{M D}$ ), and ' $t$ ' Value of Pre Test Practice Scores Between Experimental and Control Group N=60

\begin{tabular}{|c|c|c|c|c|c|}
\hline \multirow[t]{2}{*}{ Groups } & \multicolumn{5}{|c|}{ Pre-test Practice Scores } \\
\hline & Mean & Mean D & SD & $\mathbf{S E}_{\mathrm{MD}}$ & 't' value \\
\hline Experimental Group $(n=30)$ & 8.5 & \multirow[t]{2}{*}{0.47} & \multirow[t]{2}{*}{0.42} & \multirow[t]{2}{*}{.133} & \multirow[t]{2}{*}{$.255^{\mathrm{NS}}$} \\
\hline Control Group $(n=30)$ & 8.03 & & & & \\
\hline
\end{tabular}

' $t$ '(58)=2.00 P $>0.05 \mathrm{NS}=$ Not significant

The data presented in Table 3 reflects that the mean pre-test practice score (8.5) of postnatal mothers of experimental group was almost equal to mean pre-test practice score (8.03) of control group. The obtained mean difference $(0.47)$ between the pre-test practice scores of experimental and control group was found to be statistically not significant as evident from ' $t$ ' value .255 for $\mathrm{df} 58$ at 0.05 level of significance. This shows that the postnatal mothers of LBW babies in experimental and control group were homogeneous and did not differ initially in terms of their practices regarding risk factors and prevention of neonatal hypothermia before administration of health care package. 
Table 5: Mean Difference, Standard Deviation (SD), Standard Error Difference ( $\mathrm{SE}_{\mathrm{MD}}$ ), and't' Value of Post Test Practice Scores Between Experimental and Control Group N=60

\begin{tabular}{|l|c|c|c|c|c|}
\hline \multirow{2}{*}{ Groups } & \multicolumn{5}{|c|}{ Post-test Practice Scores } \\
\cline { 2 - 6 } & Mean & Mean D & SD & SE $_{\text {MD }}$ & 't' value \\
\hline Experimental Group $(n=30)$ & 15.11 & 6.35 & 1.37 & .435 & $14.57 *$ \\
\hline Control Group(n=30) & $\mathbf{8 . 7 6}$ & & & & \\
\end{tabular}

' $t$ ' $(58)=2.00$ significant at 0.05 level of significance.

The data presented in the Table 4 shows that the mean post-test practice scores (15.11) of postnatal mothers of experimental group was higher than the mean post-test practice score of control group (8.76). The obtained mean difference (6.35), between the post-test practice scores of experimental and control group was found to be statistically significant as evident from ' $t$ ' value of 14.57 for df 58 at 0.05 level of significance.

\section{Discussion Of The Findings \\ Knowledge and practice of postnatal mothers regarding hypothermia}

Finding of the present study indicated that there existed knowledge and practice deficit among postnatal mothers regarding risk factors and prevention of neonatal hypothermia. The findings are in conformity with the study finding of Bhandari, U.M. et al. (2010), which determined the knowledge and practice levels of postnatal mothers in prevention of neonatal hypothermia. The study concluded that the mothers had inadequate knowledge on prevention of hypothermia in newborn baby.

The findings of the present study that is deficit knowledge and practice among postnatal mothers regarding risk factors and prevention of neonatal hypothermia are in consistent with the finding of Padiyath, M.A. (2010), Shrestha, D. et al. (2008) which indicate that the Knowledge of mothers was inadequate in areas of thermal care, umbilical cord care and vaccine preventable diseases.

Knowledge and practice scores in the pre-test for both experimental and control group indicated that initially they did not differ in their level of knowledge and practice. But after administration of health care package, the postnatal mothers belonging to experimental group obtained significantly higher scores in the knowledge and practice test. The health care package was found to be an effective strategy in enhancing the knowledge and practice of postnatal mothers.

\section{Effectiveness of health care package on risk factors and prevention of neonatal hypothermia}

The study could not be compared in all aspects of health care package programme with other studies as no studies were conducted to evaluate the effectiveness of health care package on risk factors and prevention of neonatal hypothermia. But health care package in terms of planned teaching progamme, it was found to be an effective strategy in increasing the knowledge and practice of mothers. The finding are consistent with the findings of Tamakad, S.B.(2013), where inferred that PTP was the best teaching strategy as it enhance the knowledge of mothers regarding prevention of neonatal hypothermia.

The of findings are consistent with the findings of Ensaf, S.G. \& Sultan (2007) which concluded that educational intervention using pamphlets was successful in enhancing staff's asthma-related knowledge, attitude and management practices.

\section{Conclusion}

This is a true experimental study, conducted among 60 postnatal mothers of low birth weight infants in a selected hospital of Nepal. The findings of the study revealed that the health care package on risk factors and prevention of neonatal hypothermia was effective in enhancing the knowledge and practice of postnatal mothers of LBW.

The incidence hypothermia is still very high in developing countries which is one of the major causes of neonatal morbidity and mortality. Nurses play an important role in primary, secondary and tertiary care. Nurses are in a position to educate women in every setting. They can educate mothers regarding risk factors and prevention of neonatal hypothermia from the time of preconception.

\section{References}

[1]. Watkinson, (2006). Effect of Hypothermia in pretem. M Clin perinetol, 33(1), 43-53.

[2]. Bhandari, UM. et al. (2012).A Study to Evaluate the Effectiveness of Planned Teaching Program on Knowledge of Mothers on Prevention of Hypothermia among Newborns in Selected Hospitals of Belgaum, Karnataka. South Asian Federation of Obstetrics and Gynecology, 2(1), 89-92.

[3]. Shrestha, D. et al. (2008). Cross sectional, community based study of care of newborn infants in Nepal. $\underline{\text { British }}$ Medical Journal, 325(2) 1063.

[4]. Padiyath, M.A. (2010). Knowledge attitude and practice of neonatal care among postnatal mothers." Journal of current paediatric research, 14 (2), 147-152. 
Effectiveness of health care package on risk factors and prevention of neonatal hypothermia in ....

[5]. Tambakad, S.B. A Study to evaluate the effectiveness of planned Teaching programme on knowledge regarding prevention of neonatal hypothermia among postnatal mothers admitted in postnatal ward of KLE'S Dr. Prabhakar Kore Charitable Hospital, Belgaum, Karnataka. Published Master of Nursing thesis, K.L.E. University, Belgaum, Karnataka. 